\title{
Rainfall Prediction using Bpnn
}

\author{
M Krishna, S Mohanbabu Chowdary, Bandlamudi S B P Rani, Sanjeevi P
}

\begin{abstract}
Gauge of precipitation and ground water of an express area will assist water aid executives to preference the application of water and limit of water. The records for envisioning organized in time direction of movement i.e., functions that helpers for parent are yr, month, common precipitation, ground water level. For this conjecture lower back expanded neural frameworks with widely appealing weight replace at $n$-degree disguised layer changed into made to constrain the bungle fee and enhance the preference. Our system engaged with information estimate and statistics discernment challenge to mining process. for purchasing ANN based figure with APRIORI-NN based totally portrayal method become taken into consideration to widen and assist water aid chiefs.
\end{abstract}

Keywords: Rainfall, Prediction, NARX neural network, feed forward, back propagation.

\section{INTRODUCTION}

preferably, we could utilize a mass equalization to compute groundwater tiers using Mass in = Mass out + stockpiling, but for all intents and purposes, we will simply gauge global mass motions from estimations taken at discrete regions at discrete activities. Precipitation, energize from drift and lake levels and subsurface streams carry mass (water) into the framework, and evapo-transpiration, withdrawals (well siphoning), launch to streams, and subsurface streams take mass (water) out of the framework. In an unconfined aquifer, the adjustment away inside the aquifer is spoken to through alternate in groundwater desk as anticipated with the aid of piezometers. The alternate in groundwater desk upward push is a sort of instantly potential of quantity positioned away, contingent upon aquifer geometry.

inside the subject of hydrology, models of subsurface water streams usually require records or estimation of the hydrologic parameters of the bowl. The pressure pushed conductivity and porosity of a dirt signify how water will pass via the subsurface, but those parameters are hard to decide experimentally; it requires careful three-dimensional getting to know of the subsurface. on this way most hydrologic fashions gauge the powerful water powered conductivity and porosity from commonly few soil assessments. This paper will enterprise to display groundwater tiers with no unequivocal facts of the dirt parameters of the bowl. via making prepared an AI version, the parameters and masses will verifiably speak to the effective soil parameters of the bowl. in place of bowl soil

Revised Manuscript Received on April 12, 2019.

M Krishna, Department of CSE, Sir C R Reddy College of Engineering, Eluru.A.P, India. (marlapallikrishna@gmail.com)

S MohanbabuChowdary, Department of CSE, Sir C R Reddy College of Engineering, Eluru.A.P, India. (mohanbabus2009@gmail.com)

Bandlamudi S B P Rani, Department of CSE, Sir C R Reddy College of Engineering, Eluru.A.P, India.(bsbprani.425@gmail.com)

Sanjeevi P,Department of CSE, Sir C R Reddy College of Engineering, Eluru.A.P, India. (perurisanjeevi@gmail.com) parameters, the contributions for the AI version for this paper will include each day weather, lake degree, and stream information.

\section{LITERATURE EVALUATE}

Neha Khandelwal et al. [8] displayed a MLR situation to foresee precipitation utilizing 4 numerous climatic variables for Jaipur town, Rajasthan, India, for selecting the ones entertainers the writer implemented Pearson connection coefficient and in a while make use of the final results to determine the dry spell plausibility. In her paintings, she applied Jaipur precipitation dataset that is collect from the India Meteorological branch and implemented normal temperature, gasoline outflow, weight, winds heading, wind speed. within the wake of doing whole investigation of the data they separate beneficial information for the exam sector due to the fact there are this form of large range of additives that have extra noteworthy effect at the environment. simply so they put off a few climatic elements.

Folorunsho Olaiya [9], explore the usage of facts mining tactics in figuring out precipitation, maximum hot temperature, vanishing and wind pace. This paintings he completed making use of artificial Neural community and decision Tree calculation. He carried out meteorological records collected someplace within the range of 2000 and 2009 from the city of Ibadan, Nigeria. In his artwork he implemented C5 desire tree order calculation to create desire tree and guidelines for characterizing climate parameter viz. most extreme and least temperature, precipitation, vanishing, wind velocity as a long way as month and 365 days. His works display how this parameter has impacted the climate visible in the ones months over the research time frame.

Paras et al. [10] built up the version for weather guaging. They said it is straightforward in mild of the fact that it makes use of number one numerical circumstance. The recorded climate information that's time association records, of a selected station. They predicted greatest and least temperature, relative stickiness. Relative dampness likewise expected utilizing time arrangement of maximum immoderate and least temperature and precipitation. model is acquired from MLR situation and the coefficient of these relapses has been implemented to assess the destiny climate conditions. His version demonstrates that the assessed consequences are tasteful.

P. Hemalatha [11], carried out choice tree order plan to predicate the climate forecast for direction of supply making use of international Positioning device (GPS). GPS enables in spotting the area wherein the deliver is as of now 
exploring. The meteorological forecast on that area is contrasted and the modern database and desire is made as according to the yield have been given from the records Mining method. This desire about the weather kingdom of the exploring way is then taught to the ship. In her investigations, they positioned GPS transmitter in the supply and recipient inside the training station.

next, they broke down meteorological forecast database is the education statistics and desire tree evolved from the ones steering informational index. The GPS transmitter sends the data of the scope and longitude of its present position to the adjoining satellite tv for $\mathrm{pc}$ television for $\mathrm{pc}$ and the satellite tv for pc sends this data to the nearest satellite tv for $\mathrm{pc}$ of teaching station. The beneficiary within the education station receives the GPS records and the weather facts for that precise place is collected. After that the selection Tree is crossed making use of this weather data and the desired data is gotten and predicted choice sent to supply and supply explores consistent with expected outcomes.

Badhiye S.S. et al. [12] exhibited a writing review on temperature and moistness records studies for destiny functions forecast using amazing information mining device. In his evaluate, he discovered that adequate-Nearest Neighbor association is a honest and easy to actualize grouping method. no matter its effortlessness; it can carry out nicely with the aid of the usage of and massive. okayNearestNeighbour is especially suitable for multi-modular instructions simply as applications in which an object may have many elegance names.

Kalyankaret. al. [13] exhibited a paper on investigating the meteorological facts utilising statistics mining approach. They linked information Discovery machine to remove gaining knowledge of from Gaza town climate dataset and associated the Clustering data mining strategies.

S. Mohan et al. [14] tested about the information mining software in water asset. Water asset information has much fluctuation while you don't forget that they speaks to ordinary surprise along those strains this inconstancy makes the demonstrating as a difficult machine. The continual checking of water property commenced out as of past due and records can also produces hourly, every day, month to month, every yr and so on. particularly, in step with usage of records mining, the database is probably organized into magnificence as an instance ground water hydrology and groundwater hydrology.

In ground Water Hydrology, Rainfall and its associated spillover, vanishing from water bodies and repositories, which directs movement downstream, are the important thing segments of the floor water hydrology. the expectancy precision of the initial components guarantees the dependability on the determined repository operational approach. The prescient facts mining systems viz. counterfeit neural machine, Navie Bayesian and so on can also additionally practice.

In groundwater hydrology, growing water requests because of urbanization accentuates the want of groundwater asset for future manageability. this case propelled the experts in demonstrating the groundwater to an unusual country of exactness by way of way of becoming a member of the elements. Groundwater fashions mimic the

variance in water stage because of energize or launch from the aquifer over a time body and spatial move.

steady checking of notion wells advised analysts to create records pushed fashions as an opportunity for numerical displaying. To extricate the data of this massive groundwater database, records mining calculations are connected by manner of scientists. it's miles visible that however the reality that contrasted with floor water facts, the groundwater database has a greater drawn out statistics history, usage of data mining is as yet an unexplored territory and it has large studies potential in groundwater showing. Counterfeit neural device and association Rule Mining (outstanding information displaying) and so forth can also follow.

Nikhil Sethi et al. [15], exhibited paper on research of the information digging strategies for waiting for the precipitation and its utilization for ranchers and farming. He pointed out every observational and dynamical methodologies. He performed observational measurable examinations to assess the precision of precipitation forecast utilizing a couple of Linear Regression (MLR) assessment and applied the territorial precipitation statistics taken from Udaipur city, Rajasthan, India. Precipitation, overcast spread, normal temperature and vapor weights implemented as signs. There examinations included statistics amassing, records pre-coping with and facts determination, decrease of logical indicator, constructing version using relapse and legitimacy test. Accumulation of data is maximum great piece of this wellknown technique. The climate dataset gathered from Indian meteorological workplace which is in exceed expectations form on month to month virtually as each yr premise. They expelled a few loud and undesirable data and stuffed the lacking an incentive as a detail of records pre-handling. the chosen the pertinent information from the database for finding out the connection of records. After that they faded the signs which have excessive bury reference to others in slight of the fact that severa profoundly entomb related illustrative elements may additionally moreover drastically build the sorting out form of the relapse coefficients, and corrupt the model prescient capability. After lower of logical signs, they gather model with the usage of getting ready facts making use of direct relapse process. The model office work over getting equipped informational collection with take a look at with take a look at facts to test the exactness.

\section{METHODOLOGY}

on this paper we've three extraordinary stages of information clarification. they are

1) statistics Mining.

2) data Prediction.

3) information Visualization.

For these three areas we've got a consecutive technique of different counts and those are explained in next coming tiers and how they capacities may even adjusted over there. this is an expending point, joining RAIN FALL and floor WATER over prolonged lengths of range to make a 
noteworthy bits of understanding and from within the first region gave records PREDICTION set of rules take places. here for conjecture computation 2 critical advances had been considered, our predicting plan of truths is $\mathrm{y}(\mathrm{t})$, input realities is given with the manual of $\mathrm{x}(\mathrm{t})$ and broadly appealing weight invigorating given via $w(t)$. set of regulations is imagined in Fig. 1. Likewise, territory of BPNN is showed up in Fig. 2.

\section{ALGORITHM FOR PREDICTION}

A neuron in an artificial neural network is:

1. A set of input values (xi) with associated weights (wi)

2. An input function ( $g$ ) that sums the weights and maps the results to an output function(y).

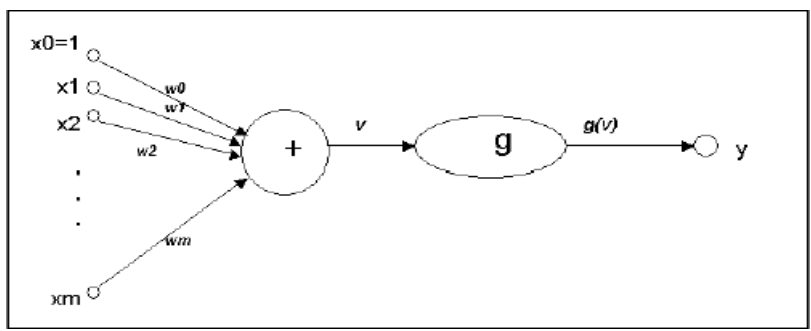

Fig. 1.Visualization of Prediction Algorithm.

Neurons are looked after out into the accompanying layers: enter, covered up, and yield. The information layer is made no longer out of complete neurons, however without a doubt of the qualities in a document which can be contributions to the following layer of neurons. the subsequent layer is the hid layer of which there will be a few. The remaining layer is the yield layer, in which there's one hub for each class. A solitary range ahead via the device consequences inside the mission of an incentive to every yield hub. The report is relegated to the beauty hub with the most noteworthy nicely really worth.

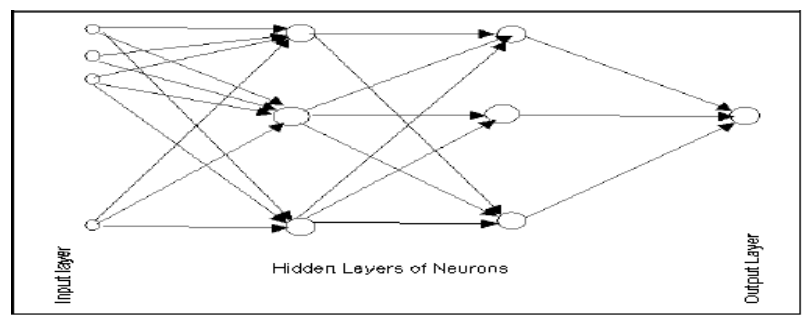

Fig. 2. The Structure of BPNN

\subsection{TRAINING AN ARTIFICIAL NEURAL NETWORK}

inside the method starting stage, the right elegance for each document is thought (i.e., oversaw getting ready), and the yield facilities can be doled out proper traits - 1 for the center component identifying with the right magnificence, and 0 for the others. effects were decided the usage of estimations of 0. nine and zero.1, independently. on this manner, it is viable to interrupt down the framework's resolved traits for the yield middle points to the ones correct tendencies, and discern an mistakes term for each middle point. these goof terms are then used to trade the thousands inside the concealed layers with the goal that at a few aspect factor across the yield regards might be closer to the right traits.

\subsection{THE ITERATIVE reading method}

A key aspect of neural frameworks is an iterative studying way in which information (segments) are familiar with the framework every one for this reason, and the thousands related to the facts regards are adjusted every time. anyhow times are displayed, the technique as often as feasible starts thru and via the use of all over again. at some stage in this gaining knowledge of stage, the framework receives ready via changing the hundreds to are expecting the proper beauty feature of facts checks. extremely good situations of neural frameworks consolidate their high versatility to uproarious statistics, in addition as their potential to painting plans on which they have got not been readied. The most notable neural framework estimation is the again-spread remember proposed at some point of the Nineteen Eighties.

at the element whilst a framework has been sorted out for a particular software, that framework is set up to be readied. to begin this technique, the simple burdens are picked discretionarily. subsequent, the readiness begins offevolved.

The framework shapes the records in the arrangement data each one consequently the usage of the lots and boundaries within the covered layers through then breaks down the consequent yields towards the right yields. Slipamericaare then incited once more thru the structure, inflicting the gadget to alter the hundreds for the accompanying document. This technique happens once more because the masses are reliably changed. during the planning of a framework, a similar route of action of records is sorted usually due to the fact the association burdens are constantly diffused.

word that multiple frameworks in no way study. this will be in moderate of the reality that the statistics does no longer contain an appropriate statistics from which the pleasant yield is resolved. Frameworks moreover might not meet if there isn't adequate information to allow whole studying. preferably, there want to be good enough facts open to make a Validation Set.

\subsection{FEED beforehand, again PROPAGATION}

The feed ahead, returned-unfold plan became made in the mid 1970s thru multiple independent assets (Werbor, Parker, Rumelhart, Hinton, and Williams). This free co-progression changed into the delayed final results of a duplication of articles and talks at diverse get-togethers that energized the complete enterprise. At gift, this synergistically made againspread plan is the maximum unmistakable and convincing version for complicated, multi-layered frameworks. Its most crucial remarkable is in non-right away responses for not all around described troubles. The common back-inciting framework has a records layer, a yield layer, and in any event one disguised layer. Theoretically, there may be no confinement on the quantity of disguised layers, yet usually there are only a couple. more than one examinations have proven that the tough and fast amount of layers predicted to deal with troubles of any unusualness is 5 (one facts layer, 3 covered layers, and a yield layer). every layer is definitely related with the succeeding layer. 
The planning method typically uses a few form of the Delta Rule, which starts with the decided distinction between the genuine yields and the nice yields. using this slip-up, affiliation burdens are extended in degree to the screw up times, which can be a scaling trouble for trendy precision. This infers the data belongings, the yield, and the suitable yield all need to be handy at a similar looking after detail. The maximum uncommon little bit of this rely is making feel of which information contributed the most to a combined up yield and how to regulate the commitment to address the screw up. (A torpid middle thing would no longer upload to the misstep and would haven't any convincing motivation to exchange its hundreds.) to deal with this trouble, getting organized statistics sources are associated with the statistics layer of the framework, and wished yields are examined at the yield layer. throughout the getting to know method, a in advance range is made through the framework, and the yield of each segment is figured layer via layer. The difference the various yield of the very last layer and the precise yield is decrease backspread to the beyond layer(s), for the most element modified by way of way of the subordinate of the trade paintings. The affiliation burdens are continuously adjusted the use of the Delta Rule. This technique proceeds for the beyond layer(s) until the facts layer is come to.

\subsection{STRUCTURING THE network}

the quantity of layers and the quantity of looking after components in keeping with layer are critical selections. To a feed forward, those parameters once more-multiplication topology, are moreover the maximum ethereal they may be the art of the framework fashioner. there's no quantifiable, brilliant reaction to the corporation of the framework for a selected utility. There are simplest three trendy necessities gotten after a while and prominent through maximum professionals and architects making use of this designing to their issues.

famous One: as the multifaceted nature within the association between the statistics and the precise yield manufactures, the amount of the coping with components inside the protected layer should in like way increase.

famous : If the approach being exhibited is separable into distinctive degrees, by using way of then extra included layer(s) may be required. If the method is not unmistakable into degrees, via the usage of then additional layers may also moreover essentially permit upkeep of the schooling Set, and now not a certifiable popular course of motion.

tenet 3: the share of making plans information open gadgets an higher set out inside the route of the quantity of looking after segments inside the protected layer(s). to check in this better certain, use the amount of instances within the training Set and partition that wide range through using the combination of the amount of center points within the facts and yield layers in the framework. through manner of then phase that stop end result over again via a scaling detail a few location in the scope of five and ten. more scaling factors are used for typically plenty less uproarious information. In case an over the pinnacle sort of phony neurons are used, the training Set can be recollected, not summed up, and the framework may be purposeless on new instructional lists.

\subsection{ENSEMBLE techniques}

XLMiner V2015 offers top notch outfit strategies to be used with Neural Networks: stowing (bootstrap storing up) and boosting. The Neural Networks set of policies in solitude may be used to find one model that results in terrific dreams for the brand new facts. we can see the reports and perplexity structures of the prevailing marker to check whether our version is a robust healthful to the statistics, besides with the useful resource of what approach may additionally we recognize whether or not there's a higher pointer essentially preserving it collectively than be observed? The proper reaction is that we do not have the foggiest idea whether or now not a normal pointer exists. Regardless, troupe methodologies empower us to sign up for numerous prone neural frameworks which, while taken collectively shape some other, continuously genuine robust neural frameworks. those methodologies paintings by way of approach of creating distinct grouped frameworks, by way of way of taking extraordinary instances of the primary dataset, and after that combining their yields. (Yields may be joined by a couple of techniques as an instance, lion's offer vote for request and averaging for estimate.) this aggregate of models successfully decreases the adjustment within the strong model. the 2 unmistakable kinds of collecting methodologies provided in XLMiner (urgent and boosting) range on 3 things: 1) the choice of making plans data for each pointer or inclined model; 2) how the inclined fashions are made; and three) how the yields are blended. In all the 3 structures, every fragile model is set up general schooling Set to land up capable in a few piece of the educational listing.

Sacking (bootstrap conglomerating) changed into one of the leader social event computations created. pressing produces more than one training units by using the use of using unpredictable searching at with substitution (bootstrap trying out), applies the neural framework remember quantity to every datum set, through then takes the ordinary the various fashions to decide the conjectures for the modern information. The satisfactory piece of elbowroom of pressing is the relative encourage that the figuring may be parallelized, which settles on it a normal selection for fantastic instructive lists.

Boosting collects a robust model via logically making plans fashions to concentrate on facts getting erroneous foreseen tendencies in beyond models. every time finished, all markers are joined by using a weighted triumphing component vote. XLMiner gives three unmistakable assortments of boosting as performed by using the AdaBoost estimation (a champion most of the maximum favored outfit computations being applied nowadays): M1 (Freund), M1 (Breiman), and SAMME (Stagewise Additive Modeling the usage of a Multi-class Exponential).

Adaboost.M1 first designates a weight (wb(i)) to every document or popularity. This weight is earlier than the whole thing set to at least one/n, and may be revived on every accentuation of the matter. a singular neural framework is made using this initially making plans set $(\mathrm{Tb})$ and a misstep is resolved using the circumstance (1) 


$$
e_{b}=\sum_{i=1}^{n} w_{b}(i) I\left(C_{b}\left(x_{i}\right) \neq y_{i}\right)
$$

Where, the $\mathrm{I}()$ function returns 1 if true and 0 if not. The error of the network in the $\mathrm{b}^{\text {th }}$ iteration is used to calculate the constant $\alpha_{b}$. This constant is used to update the weight wb(i). In AdaBoost.M1 (Freund), the constant is calculated as

$\alpha_{b}=\ln ((1-\mathrm{eb}) / \mathrm{eb})$

In AdaBoost.M1 (Breiman), the constant is calculated as $\alpha_{b}=1 / 2 \ln ((1-\mathrm{eb}) / \mathrm{eb})$

In SAMME, the constant is calculated as

$\alpha_{b}=1 / 2 \ln ((1-\mathrm{eb}) / \mathrm{eb}+\ln (\mathrm{k}-1)$ where $\mathrm{k}$ is the number of classes

Where, the number of categories is equal to 2, SAMME behaves the same as AdaBoostBreiman.

In any of the three implementations (Freund, Breiman, or SAMME), the new weight for the $(b+1)^{\text {th }}$ iteration will be given by the following expression.

$$
w_{b+1}(i)-w_{b}(i) e^{\left(\propto_{b} I\left(C_{b}\left(x_{i}\right) \neq y_{i}\right)\right)}
$$

Afterwards, the weights are all readjusted to sum to 1 . As a result, the weights assigned to the observations that were assigned inaccurate predicted values are increased, and the burdens assigned to the recognitions which have been extraordinary actual foreseen traits are lessened. This adjustment controls the accompanying neural framework to vicinity extra highlight on the facts that had been doled out off kilter conjectures. (This dependable is furthermore used within the closing calculation, in order to provide the framework with the least bumble extra impact.) This device repeats till $b=$ extensive form of vulnerable understudies (pressured by using the use of the consumer). The estimation via then methods the weighted normal amongst each and each frail understudy and consigns that motivator to the document. Boosting commonly yields high-quality models over urgent, though, it has an harm because it is not parallelizable. in this manner, if the amount of susceptible understudies is big, boosting may now not be turning into.

Neural community Ensemble methods are specifically earth shattering methodologies and usually bring about desired execution over a unmarried framework. This aspect extension in XLMiner V2015 gives customers regularly specific preference models, and need to be taken into consideration over the single framework device.

thru and via we're shifting from estimate to define to present nearly same records near to it calls for two stages like choice 1. CLUSTERING, 2. REFINING

\section{ALGORITHM FOR MAP REDUCER}

Step1. Use MapReduce model to find the frequent 1itemsets.

Step2. Set $k=1$.
Step3.If the frequent $(k+1)$-itemsets cannot be generated, then go to Step6.

Step4. According to the frequent $k$-itemsets, use MapReduce model to generate the frequent

$(k+1)$-itemsets.

Step5. If $k$ is less than the max iteration times, then $k+$ ,+ go to Step3; Otherwise, continue to the next step.

Step6. According to the frequent itemsets $L$, generate the strong rules.

the important thing improvement in Apriori rely is to discover the ordinary itemsets. in the okay th cycle, it paperwork the sports of functionality candidates of size good enough in all the trades. it's far unmistakably that the occasions together with of candidate trouble units in a solitary alternate makes no sense with the incorporating into another change in a similar accentuation. As such, the occasions rely process in a unmarried cycle will be parallel performed. After this level, all of the occasions of candidate element units are summed up. moreover, the be part of carrying events are finished on the cutting-edge k-problem units and prune. however, residence to apriori estimation, component devices were batching in our tool through using the usage of KNN collecting plan then the ones had been supplied to manual reducing approach the use of the above figuring from degree three to degree 6 .

A department is referred to as between all concentrations in a dataset. Partition is defined because the Euclidean detachment amongand is given with the aid of the situation (three).

$$
d=\sqrt{\sum_{i=1}^{n}\left(x_{i}^{2}-y_{i}^{2}\right)}
$$

From these distances, a distance matrix is constructed between all possible pairings of points $(\mathrm{x}, \mathrm{y})$.

Each data point within the data set has a class label in the set, $\mathrm{C}=\{\mathrm{c} 1, \ldots, \mathrm{cn}\}$.

The records facilities', ok-closest acquaintances (good enough being the amount of buddies) are then found through studying the partition device. The good enough-closest records facilities are then bankrupt proper down to make experience of which magnificence call is the maximum typically perceived a few of the set. The most extensively perceived elegance imprint is then exact to the facts element being tested.

For the scenario where in any occasionelegance imprints display up a similar sort of instances for a particular information point inside the dataset, the KNN take a look at is continued taking walks on ok-1 (one a whole lot much less neighbor) of the records factor being alluded to. that is a recursive technique. In case there may be another time a tie among schooling, KNN is continued going for walks on ok2. This returns within the event of a tie until good enough $=1$. proper while $\mathrm{ok}=1$ there can be most effective one class 
addressed inside the final outcomes and thusly there may be no tie.

that is an underhanded technique for locating the restore from the instability of the water table. The climb within the water table at some point of the swirling season is used to survey the resuscitate, gave that there is an undeniable stormy season with the the rest of the yr being respectably dry. The applicable supposition that can't avoid being that the climb inside the water desk is largely a end result of the precipitation repair. it's miles seen that various variables, for instance, siphoning or water framework at some point of the stormy season don't have an effect. If the climb in water desk is $>\mathrm{Ds}$, the precipitation invigorate, $\mathrm{Ri}$ is given with the aid of the going with situation.

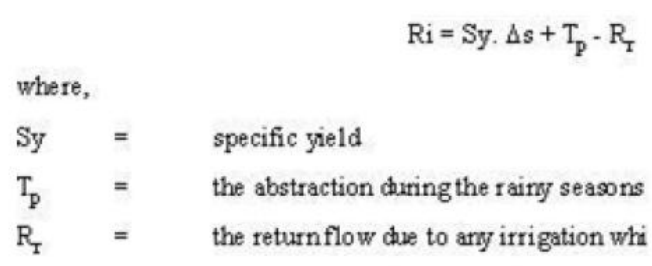

The number one issue of the above condition is that it overlooks the subsurface inflow and overflowing and expect that every influx and flood is reliably spread over the arena. this could be typically great for the precipitation and irrespective of for the get right of entry to flow into from water framework but it's miles every so often valid for the attention from the aquifer. whilst siphoning is faded or quits all through the stormy seasons, a redistribution of floor water heads takes location with the objective that little little bit of the watched addition in water level may be a quit result of common properly recuperation. additionally, the above condition is depending on the estimation of the unique yield, this is difficult to pick out for the motive that water desk instability takes place inside the halfway inundated region.

Sophocleous (1991) proposed a mutt water fluctuation approach to manipulate resuscitate estimation. This approach is frequently robust for assessing trademark ground water restore in commonly level domains with a shallow water desk (underneath $10 \mathrm{~m}$ ). through partner water table climbs with unequivocal precipitation activities and by merging the resuscitate tests from the soil water counterbalance exam with the ensuing water desk risings, you will be capable of get fruitful storativity regards for every invigorate take a look at internet site online, mainly in the wake of averaging multiple such traits. The website online-adjusted effective storativity properly well worth could then have the option to be used to decode each actual water table climb linked to a particular hurricane duration right into a bearing on share of ground water restore.

Estimation botches inside the cross breed water difference system are decreased through the use of taking walks a 'typhoon period' based soil water stability at some degree inside the time in combination with the related water degree climb. This approach offers more dependable behind schedule effects of the empower estimation than some one of a kind machine.
In general,

$$
\mathrm{I}-\mathrm{O}=\Delta \mathrm{W} / \Delta \mathrm{t}
$$

where,

$$
\begin{array}{lll}
\mathrm{I} & = & \text { inflow ( } \mathrm{m}^{3} / \text { day) during time } \Delta \mathrm{t} \\
\mathrm{O} & = & \text { outflow }\left(\mathrm{m}^{3} / \text { day }\right) \text { during time } \Delta \mathrm{t} \\
\mathrm{W} & = & \text { change in water volume }\left(\mathrm{m}^{3}\right)
\end{array}
$$

Considering the various inflow and outflow components, the ground water balance equation for a time period $t$ is

\begin{tabular}{|c|c|c|}
\hline $\mathrm{Ri}$ & & recharge from raiff all \\
\hline$R_{c}$ & $=$ & recharge from canal recharge \\
\hline$R_{T}$ & $=$ & recharge from field irrigation \\
\hline$R_{t}$ & & recharge from tank \\
\hline $\mathrm{S}_{\mathrm{i}}$ & & influent recharge from rivers \\
\hline $\mathrm{I}_{\mathrm{g}}$ & & inflow from other basins \\
\hline$E_{t}$ & & evapotr anspir ation \\
\hline$T_{p}$ & & dt aft from ground water \\
\hline $\mathrm{S}_{\mathrm{e}}$ & $=$ & effluent recharge to rivers \\
\hline $\mathrm{O}_{g}$ & $=$ & outflow to other basins \\
\hline & $=$ & change in ground water stor \\
\hline
\end{tabular}
given as.

$$
\mathrm{Ri}+\mathrm{R}_{\mathrm{c}}+\mathrm{R}_{\mathrm{r}}+\mathrm{R}_{\mathrm{t}}+\mathrm{S}_{\mathrm{i}}+\mathrm{I}_{\mathrm{g}}=\mathrm{E}_{\mathrm{t}}+\mathrm{T}_{\mathrm{p}}+\mathrm{S}_{\mathrm{e}}+\mathrm{O}_{\mathrm{g}}+\Delta \mathrm{W}
$$

where,

The above situation is the general ground water parity condition for an unconfined aquifer. The cutoff points of a locale regularly inspected don't cope with streamlines i.e., they may be no longer inverse to the equipotential line. consequently, the flat inflow and overflowing must be spoken to the equality situation.

one of the elements influencing the alternate in water table is the convincing porosity, ne, of the arena wherein the water desk instabilities stand up. ne modifications as the significance of water desk modifications, mainly for water tables under 3 meters significance. additionally, it should be seen that if the water drops, a few phase of the water is held by way of the earth particles; in case it rises, air can be gotten inside the interstices which might be stacking up with water. on this manner ne for developing water i.e., with the whole lot considered, isn't always as masses as that for a falling water desk. The above state of affairs considers best a solitary aquifer shape and does no longer communicate to bury streams among the aquifers in a multi aquifer machine.

All segments of the water equalization condition are enlisted using impartial approaches at each workable threat. Counts of water balance segments constantly include botches, as a result of shortcomings within the structures used. The distinction of water balance is given as a prepared term of the water equalization circumstance and fuses the mistake within the affirmation of the additives, which aren't taken into consideration. 
The water adjustment can be enlisted for at some thing element among time. to apply the above condition exactly, it is essential that each the quarter and the length for which the equality is studied be carefully picked. All fragments of the water parity condition apart from the precipitation restore are surveyed using the material hydrological and meteorological records. The precipitation resuscitate is dictated with the useful resource of substituting those tests in the water parity condition. This philosophy is proper for the regions wherein the one year can be secluded into rainstorm and non-storm durations and the water equality is finished freely. The past yields a degree of repair coefficient and the ultimate chooses the degree of precision with which the fragments of water parity circumstance have been assessed.

\section{RESULTS}

Here to generate prediction on RAINFALL and GROUND DATA a data set gathered for average rainfall and average temperature from the years 1901 to 2015 in Malaysia. Initially rainfall, year, month and temperature are given as input to the network.

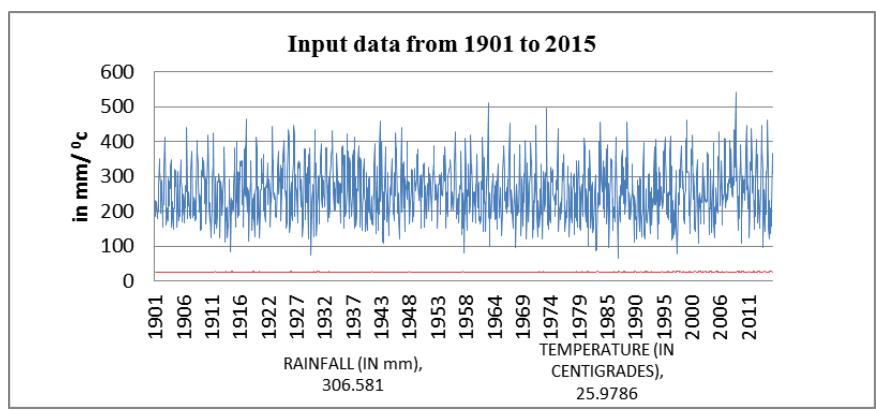

Fig. 3.Input data from the year 1901 to 2015 for RAINFALL and TEMPERATURE for every month.

Now initially rainfall needs to be predicted using ANN andtrained for the years 1901 to 2014 and was compared with only 2015 predicted data. Based weight update and error minimization approach in ANN with BACK propagation.

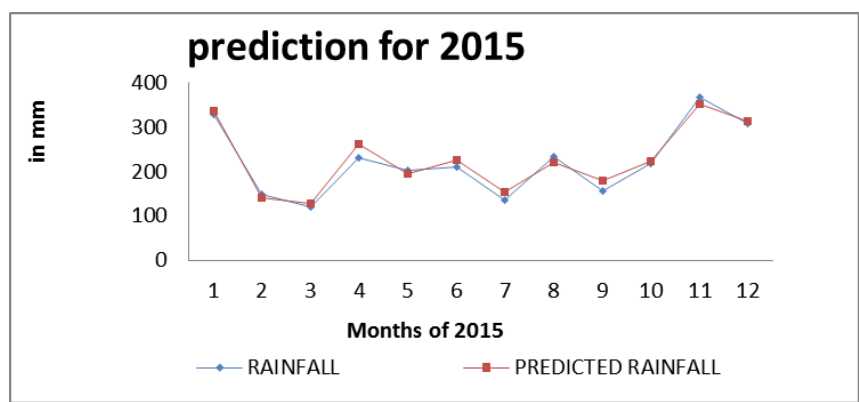

Fig. 4.Prediction and comparison with original value with error minimization values.

on this the botch a number of the number one and foreseen had been given in bins and their floating modified into given by way of best instance is aftereffect of void concealing subject and poor slanting is given via red.

\section{CONCLUSION}

This philosophy is actual for the zones wherein the year can be divided into tempest and non-rainstorm periods and the water adjustment is finished autonomously. The past yields a take a look at of restore coefficient and the final chooses the diploma of exactness with which the portions of water equalization circumstance were assessed.

\section{REFERENCES}

1. Yannan Zhao, Yuan Li, Lifen Zhang, Qiuliang Wang, Groundwater level preference for torrential slide reliant on portrayal and backslide tree, In Geodesy and Geodynamics, extent 7, problem five, 2016, Pages 348-355.

2. ZhongnanDaxueXuebao (ZiranKexue Ban)/mag of fundamental South university (generation and technology)volume 46, difficulty 6, 26 June 2015, Pages 2324-2332

3. Jinxing Lai, JunlingQiu, ZhihuaFeng, Jianxun Chen, and Haobo Fan, "desire for Soil Deformation in Tunneling the usage of artificial Neural Networks," Computational Intelligence and Neuroscience, vol. 2016, Article identity 6708183, sixteen pages, 2016.

4. Dr.Marlapalli Krishna, V Devi Satya Sri, Bandlamudi S B P Rani and G. Satyanarayana. "component based totally reliable virtual Watermarking Scheme for felony ownership" worldwide mag of natural and accomplished mathematics pp: 1291-1299, Vol-119, problem-7, 2018

5. Sri Krishna ChaitanyaRudraraju, Nakka. Desai, M. Krishna and Bandlamudi S. B. P Rani. "facts MINING IN CLOUD COMPUTING: A overview", magazine of superior research in Dynamical and control systems, pp: 1198-1207, Vol-nine, problem-18, 2017.

6. D. J. Armaghani, M. Hajihassani, B. Y. Bejarbaneh, A. Marto, and E. T. Mohamad, "Winding volume of shale shear great parameters via strategies for shake report exams thru an advanced phony neural framework," size, vol. 55, pp. 487498, 2014

7. okKoteswara Chari and M Krishna. "An green Scalable facts Sharing in Cloud garage using Key combination Encryption", international journal of technology Engineering and improve generation, 3(11), pp: 945-946, Nov-2015.

8. KavithaParavathaneni and M. Krishna. "Unadulterated photo Noises and Discrepancy Estimation", worldwide magazine for Technological studies in Engineering, three(7), pp: 15011503, Mar-2016.

9. D Paul Joseph, M Krishna and good enough Arun. "Scholarly Analytics and evaluation of Symmetric and uneven Cryptography Algorithms", global magazine of research studies in laptop technological know-how and Engineering (IJRSCSE), 2(three), pp: sixty three-sixty eight., Mar-2015.

10. Paras, Sanjay Mathur (2012) A easy climate Forecasting version the use of Mathematical Regression. Indian research journal of Extension education special trouble Vol.( I), 2012; 161-168.

11. P.Hemalatha (2013) Implementation of records Mining technique for weather report steerage for Ships the usage of worldwide Positioning machine. All inclusive magazine of Computational Engineering studies Vol. (3); 198-202.

12. S.S. Badhiye, Chatur P.N. likewise, Wakode B.V. (2013) Temperature and Humidity statistics evaluation for future Values Prediction the use of Clustering method: An technique. All inclusive journal of Computational Engineering studies Vol. (three) ; 198-202. 
13. M. A. Kalyankar, S.J. Alspurkar (2013) information Mining approach to investigate the Metrological facts. big journal of boost research in laptop science and software Engineering Vol 3 (2); 114-118.

14. S. Mohan , N. Ramsundram (2013) data-burrowing fashions for water aid programs. ISH magazine of Hydraulic Engineering. Vol.19 (3); 211-218.

15. N. Sethi, KanwalGarg (2014) Exploiting information Mining techniques for Rainfall Prediction. tremendous journal of laptop technological information and information technology Vol. five (3), 2014; 3982-3984.

16. D. Chouhan, Jawahar Thakur (2014) statistics Mining method for climate Prediction : A evaluation. huge magazine of new and Innovation trends in Computing and verbal exchange Vol. 2 (eight); 2184-2189.

17. Marlapalli Krishna, G. Srinivas and Prasad Reddy PVGD. "picture Smoothening and Morphological Operator based JPEG Compression", magazine of Theoretical and accomplished records era, pp: 252-259, Vol: eighty five, No: 3, Mar-2016.

18. Marlapalli Krishna, Prasad Reddy PVGD, G. Srinivas and Ch. Ramesh."A smoothening primarily based JPEG weight for an objective photograph nature of popular and disorderly snap shots", worldwide mag Of applied Engineering and research, pp: 3799-3804, Vol:11, No:6, 2016.

19. Krishna M., Chaitanya D. okay.,Soni L., Bandlamudi S.B.P.R., Karri., R.R.: (2019), "loose and allotted get entry to to Encrypted Cloud Databases". In: Omar S., Haji Suhaili W., Phon-Amnuaisuk S. (eds) Computational Intelligence in records structures. CIIS 2018. Advances in clever systems and Computing, vol 888. pp 107-116, Springer Nature. DOI: 10.1007/978-three-030-03302-6_10.

20. Dr.Marlapalli Krishna, Bandlamudi S B P Rani, V Devi Satya Sri and Dr. Rama Rao Karri. "Channel based totally Jpeg Compression for Noisy photos" journal of superior studies in Dynamical and manage systems, pp: 1233-1248, Vol-nine, hassle-18, 2017.

21. KothapalliChaitanyaDeepthi, Dasari Ashok and $\operatorname{Dr} M$ Krishna. "A multi capability CP-ABE get admission to manipulate scheme for open conveyed stockpiling", global assembling on pc imaginative and prescient and AI, IOP Conf. Plan: mag of Physics: Conf. sport plan 1228 (2019).

22. V Pranav, P Satish Kumar and Dr M Krishna. "Execution exam of dispersed registering for valid applications", global assembling on laptop imaginative and prescient and AI, IOP Conf. direction of action: mag of Physics: Conf. recreation plan 1228 (2019).

23. okPurnaPrakash, Dr M Krishna and M Satya Vijaya. "information useful network maintaining apart the use of giant learning based totally absolutely recommender version", international assembling on pc vision and AI, IOP Conf. sport plan: journal of Physics: Conf. recreation plan 1228 (2019).

24. Dr. M. Krishna. "The VLIW architecture for actual-Time depth Detection in photograph Processing", worldwide magazine of computer technological information and Mechatronics, pp: 1-nine, Vol.2.trouble.VI, Dec-2016.

25. Dr. M. Krishna. "An green Multi Dimensional view for vehicles with the resource of Patch memory the board in picture making plans", international journal of computer era and Mechatronics, PP:1-10, Vol.1.problem.V, Dec-2016. 